\title{
PREDICTION OF CREEP STRAIN IN MINERAL WOOL SLABS UNDER COMPRESSION
}

\author{
Laimutis Steponaitis ${ }^{1}$, Sigitas Vëjelis ${ }^{2}$ \\ 1,2 Vilnius Gediminas Technical University, Sauletekio al. 11, LT-10223 Vilnius. \\ E-mail:Ilais@termo.vgtu.lt (corresponding author); ${ }^{2}$ sigitas.vejelis@vgtu.lt
}

\begin{abstract}
In order to successfully use stone wool products as a construction material which is affected by long-term compressive loads, it is not enough to be aware of the strength and deformation characteristics determined under shortterm loads. It is important to know the change in time of deformations (creep deformations) of the products under constant long-term compressive loads, which cause the enlarged deformations of structural elements of the material.

The analysis of the change in thickness of stone wool under constant short-term and long-term $\left(\sigma_{c}=0.25 \div 0.60 \sigma_{10 \%}\right)$ loads is presented, predicted values of creep deformations are determined and combined using synthesis procedure, impact factors for joint prediction results and weighted mean values of joint prediction results are determined. For the prediction of consistent pattern of creep deformations for the period of 10 years the relative creep deformations at the time $t$ were used. These relative deformations under constant compressive stress $\sigma_{c}$ were recalculated to single stress. It has been proposed to evaluate predicted creep deformations of stone wool slabs for any of the constant compressive stress $\sigma_{c}=0.25 \div 0.35 \sigma_{10 \%}$, representing the time period up to 10 years, on the basis of values of creep mobility.
\end{abstract}

Keywords: mineral wool, compressive strength, creep strain, prediction

\section{Introduction}

Stone wool layers, which insulate multi-layered partitions, in most cases are affected by long-term compressive stress (Horwath 1997), consequently, the prediction of their creep deformations is very important from both scientific and practical point of view (Horvarth 1997, 1998; Gnip et al. 2012b, 2013). The most reliable data on these deformations may be obtained from long-term experiments. However, such data practically cannot be found in literature, because these experiments are complex and long-term, it is important to carry out short-term tests and extrapolate obtained results for a longer time (Žiliukas 2004; Gnip et al.2007, 2009). Moreover, if in the case of expanded polystyrene products their mechanical properties with the confidence level of $90-95 \%$ may be related with their density (Gnip et al.2005, 2007, 2012b; Vaitkus 2007; Mihlaynlar et al. 2008), in the case of stone wool products such data cannot be easily systemized due to anisotropic structure, especially when it is crimped (Bergonnier et al. 2005; Karamanos 2007; Gnip et al. 2009) because compressive and other loads are received by unevenly distributed inter fibre contacts (Gnip et al. 2012b). Mechanical behaviour of stone wool products under long-term loads is significantly different from the behaviour of the material under short-term loads (Merkel 2002). Consequently, it is very important to know how deformations (creep deformations) of stone wool products develop over time, i.e. how they deform over time under the same constant long-term loads (under fixed stress) which influence the enlarged deformability of structural elements of the material (Leal et al. 2009; Gnip et al. 2012b).

Creep process is usually approximated by the calculation model numerical parameters of which are based on time-limited test results and the assumption that the chosen deformation mechanism applies outside the direct experiment limits (Žiliukas 2004; Gnip et al. 2012b).

In the European countries, mineral wool insulation creep tests under compressive load are governed by normative documents (EN 1606:2013; EN 13162:2012). Based on these normative documents creep deformations of thermal insulation materials do not exceed $2 \%$. In order to limit deformations of thermal insulating materials to $2 \%$, it is important to (Merkel 2002; Gnip et al. 2012a) maintain the initial stage of creep deformations by introducing safety factor (coefficient) and ensure the long-term thermal insulation characteristics throughout its operation (protect from moisture, high temperatures, etc.).

The aim of the work is to experimentally determine the indicators of stone wool products under short-term and long-term loads and on their basis to evaluate predicted values of creep deformations for the period of 10 years.

\section{Materials and test methods}

Before the long-term creep tests in accordance with $E N 826$, the strength and deformation characteristics of stone wool slabs under short-term compressive load have been determined. For the purpose of evaluation of statistical results in each series of tests a group of specimens possibly close with regard to their characteristics have been tested. Long-term compression tests have been performed on fourteenth series of such specimens. The results of statistical processing of the data are presented in Table 1. Long-term creep test modes have been chosen using strength and initial modulus of elasticity values (Table 1) of stone wool specimens under compression.

The overall deformation of specimens under constant load has been given by the equation:

$$
X_{t}=X_{0}+m(\sigma) \cdot t^{b(\sigma)} \text {, }
$$


From equation (1) the part of creep deformations is expressed as:

$$
X_{c t}=X t-X_{0}=m(\sigma) \cdot t^{b(\sigma)},
$$

where: $X_{0}$ - initial deformation after $60 \mathrm{~s}$;

$X_{c t}$ - creep deformation after the time $t$;

$m, \quad b-$ parameters of the material (FINDLEY parameters).

Deformations that develop in stone wool specimens under constant compressive load consist of relatively instantaneous deformation $\varepsilon_{0}$ occurring immediately after the addition of the load, and later developing deformation $\varepsilon_{c}(t)$ :

$$
\varepsilon(t)=\varepsilon_{0}+\varepsilon_{c}(t)
$$

Experimental data is obtained when:

$$
\begin{aligned}
& \varepsilon_{0}=\frac{X_{0}(t=60 s)}{\overline{d_{s}}}, \text { then } \\
& \varepsilon_{c}(t)=\frac{X(t)-X_{0}(t=60 s)}{\overline{d_{s}}}=\frac{X_{C}(t)}{\overline{d_{s}}},
\end{aligned}
$$

$X(t)$ - thickness reduction of stone wool specimens, mm, at fixed time $t ; \bar{d}_{s}-$ mean value of thicknesses (heights) of tested specimens with initial load of $250 \mathrm{~Pa}$, $\mathrm{mm}$, (it 5 specimens at each stress level were tested).

Phenomenological function $F\left[\varepsilon_{c}(t)\right]$ description is based on two assumptions. One of them,- is that the creep rate decreases at a gradual, "very agile" carrier amount reduction of elementary deformations and gradually "slower' their intigration into the process of deformation. In this case, creep $\varepsilon_{c}(t)$ is a well-established process and creep deformations can be expressed by equations (EN 1606):

$\bar{\varepsilon}_{c}(t)=b_{0} t_{1}^{b}$,

where: $\bar{\varepsilon}_{c}(t)-$ mean value of creep deformation at the moment $t, \% ; b_{0}, b_{1}$ - constants depending on the characteristics of the material; $t$ - time, hours.

Another assumption is based on the fact that the creep rate decrease over time is caused by the reduction of elementary deformation carriers at the constant agility of each carrier.

Creep is the extinguishing process and the relationship between creep deformations $\varepsilon_{c}(t)$ and time $t$ is exponential (Gnip et al. 2009):

$\bar{\varepsilon}_{c}(t)=b_{0}\left[1-\exp \left(-b_{1} \cdot t_{2}^{b}\right)\right]$,

where: $b_{0}-\bar{\varepsilon}_{c}$ value when $t \rightarrow \infty ; t-$ time, days.

\section{Creep deformations test results}

Thirteen sets of specimens were produced from partially crimped structure slabs with the density of $(95-108) \mathrm{kg} / \mathrm{m}^{3}$ and (3.4-6.1) \% of binder. One set of specimens (No. 11) had vertically layered structure with the density of (60-95) kg/m $\mathrm{m}^{3}$ and $(3.2-4.8) \%$ of binder.

Fig. 1 presents experimental curves of thickness (height) reduction $X_{c}(t)$ of stone wool specimens under long-term compressive load. The values $X_{c}(t)$ of stone wool slabs have been approximated in accordance with the equation (2).

Relative creep deformation $\varepsilon_{c}(t)$ values were calculated according to equations (6) and (7). The corresponding mathematical statistical processing of the results is presented in Table 1. The Table for each creep test series include:

- information about the selected stone wool specimens (density, compressive stress $\sigma_{10 \%}$ deformation $\varepsilon_{c}$ );

- mean value of thickness of test specimens;

- values of long-term compressive load as well as deformation $\varepsilon_{0}$ occurring at the time of loading, and $\varepsilon_{c}(t)$, which develops until the end of the experiment.

- constant (power law) equation coefficients $b_{0}$ and $b_{l}$, (exponential) coefficients $b_{0}, b_{1}, b_{2}$, and accordingly mean average standard deviation $S_{r}$ and coefficients of determination $R_{\varepsilon_{c} \cdot t}^{2}$;

- calculated predicted creep deformations dotted values when constant compressive load operates for 4,8 and 10 years.

The statistical analysis of experimental data has shown that,- assessing the errors approximation of creep deformation using regression equations (6) and (7),equally well describe the results (Fig. 2). Therefore, it is not possible to give a preference for one or another of the proposed dependencies. However, the empirical dependence (6) does not satisfy the creep deformations limit conditions, when $b_{1}>0, t \rightarrow \infty$.

Dependence (7) sufficiently describes the results and satisfies creep deformations and speed development limit conditions, when $b_{l}>0, t \rightarrow \infty$. Creep deformation $\bar{\varepsilon}_{c}(t)$ values as well as mean values of relative creep deformations $\bar{\varepsilon}_{c}(t \rightarrow \infty)=b_{0}$ may be calculated according to (7) empirical dependence at any time including when $t \rightarrow \infty$.

Predicted values of the relative difference of creep deformations $\bar{\varepsilon}_{C}(T=10), \%$ have been calculated as follows: 
a)

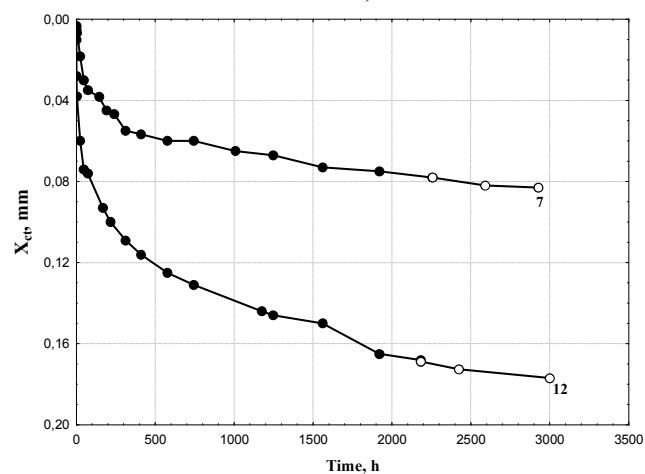

b)

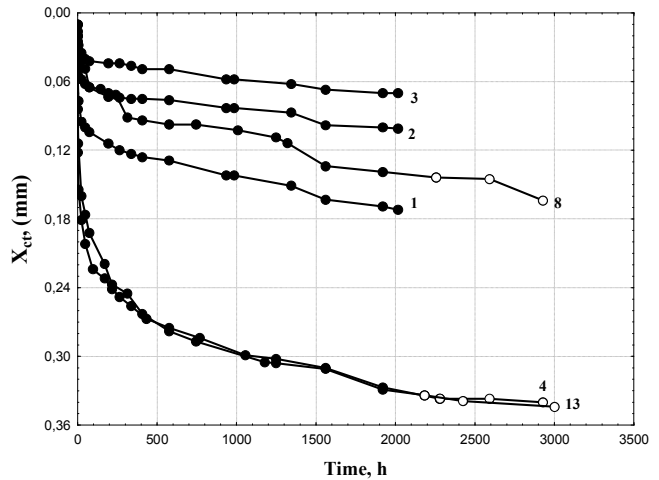

c)

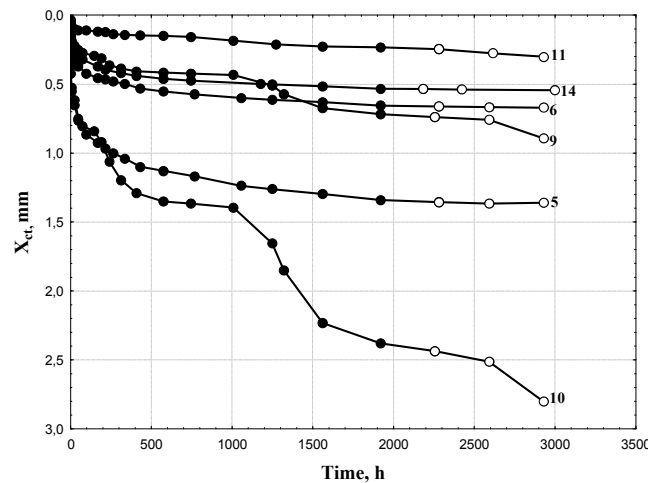

Fig. 1. Kinetics of the change in thickness of stone wool under constant long-term compressive load $\boldsymbol{\sigma}_{c}=\mathbf{0 , 2 5} \cdot \boldsymbol{\sigma}_{10 \%}$ (a), $\boldsymbol{\sigma}_{c}=\mathbf{0 , 3 5} \cdot \boldsymbol{\sigma}_{10 \%}$ (b) and $\boldsymbol{\sigma}_{c}=\mathbf{0 , 4 - 0 , 6} \cdot \sigma_{10 \%}$; the lines indicate the test series numbers (other indicators are presented in Table 1). Experiments duration: - - up to 90 days; $\circ$ - more than 90 days.

$\bar{\varepsilon}_{c}(T=10)=\frac{\bar{\varepsilon}_{c(1)}(T=10)-\bar{\varepsilon}_{c(2)}(T=10)}{\bar{\varepsilon}_{c(1)}(T=10)} \cdot 100$,

$\bar{\varepsilon}_{c(1)}(T=10)$ ir $\bar{\varepsilon}_{c(2)}(T=10)$ - predicted creep deformation values for 10 years period calculated in accordance with the power law (6) and the exponential (7) equations.

Extrapolating on the basis of exponential equation (7), the predicted values of creep deformations for 10 years period are on averagel by $16 \%$ lower except for the three $=$ individual deviations $\varepsilon_{c}(t=10)$ that reach $(28-57) \%$. It should be also noted that the extrapolation method is rather crude operation and is based on a series of assumptions, consequently, it is assumed that the confidence probability is (70-95)\% (Gnip et al. 2009). Since differences of predicted creep deformation values are set by going very far from a direct experimental time range, it suggests that prediction results $\left(T_{\text {power }}=10\right)$, and $\left(T_{\text {exponential }}=10\right)$ is not in conflict with each other, they are compatible.

a)

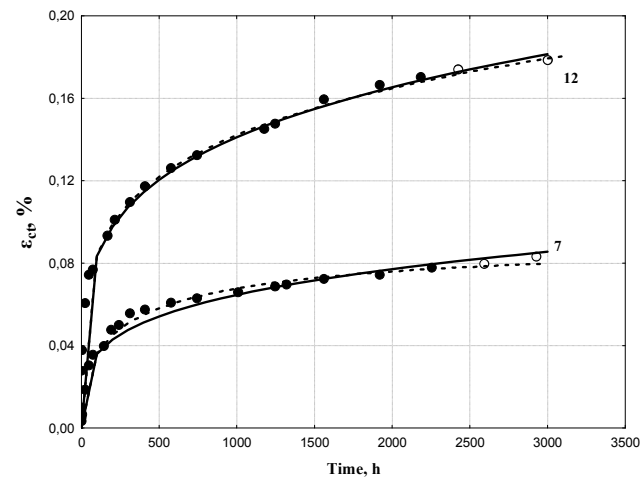

b)

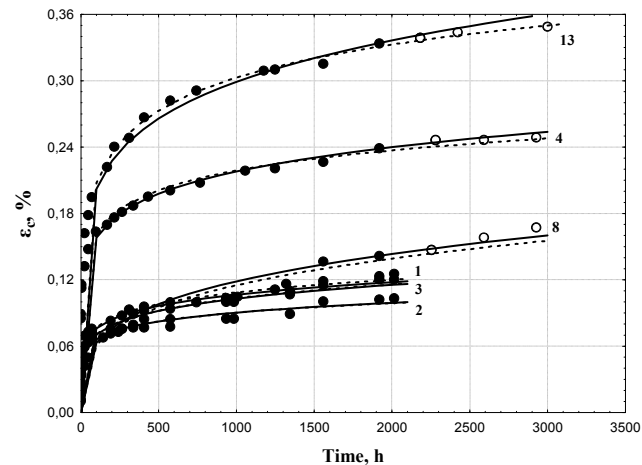

c)

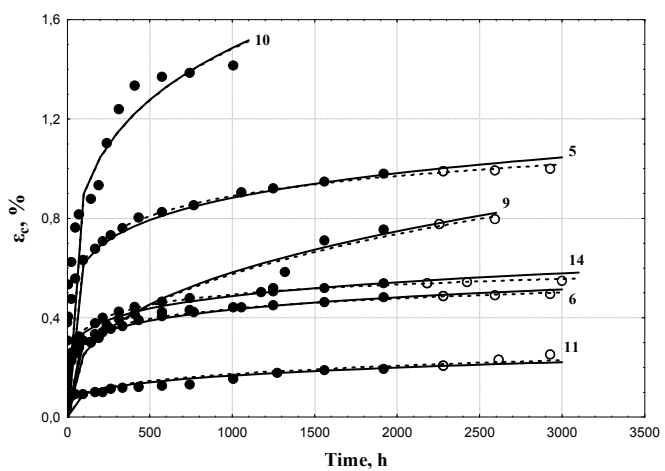

Fig. 2. Creep deformations growth kinetics of different densities stone wool specimens (experimental data) under constant fixed compressive load $\sigma_{c}=\mathbf{0 , 2 5} \cdot \boldsymbol{\sigma}_{10 \%}$ (a), $\sigma_{c}=\mathbf{0 , 3 5} \cdot \sigma_{10 \%}$

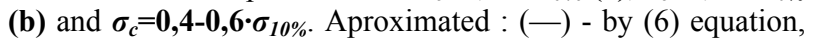
(---) by (7) equation. Experiments duration: - - up to 90 days; o - more than 90 days.

Adopting the predicted results consistency condition and assessing their reliability, prediction synthesis procedure can be realized. Its essence - is as follows: predicted values obtained from power law (2) and an exponential equation (3) weighted average result 
determination. The less reliable the individual score, the lower is its weighted contribution to the combined prediction which should be much more reliable than its components (Gnip et al. 2008, 2009; Vaitkus 2007).

Further, the specific synthesis procedure of predicted values is presented. Based on the results obtained from equations (6) and (7), and,- their errors characterized by mean square deviations are calculated (see Table 1).

In Fig. 3.- the comparison of predicted dotted $\bar{\varepsilon}_{c}(t)(T=10)$ values calculated from power law (6), and exponential (7) equations are presented.

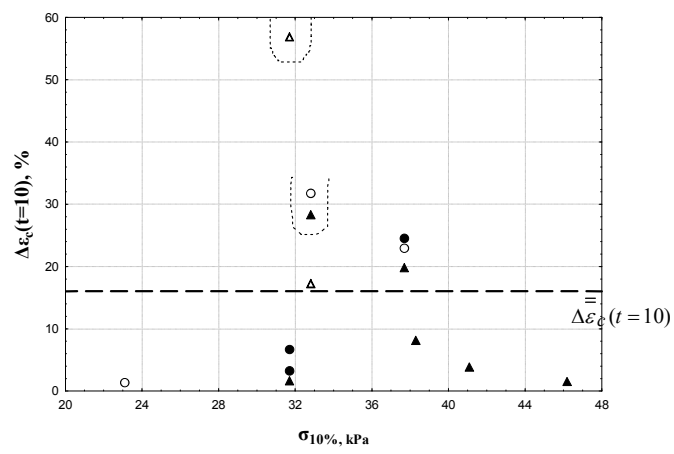

Fig. 3. Stone wool slabs under constant compressive load $\sigma_{c}$ creep deformations (for 10 years period) predicted values reduction calculated according to the exponential equation compared with the corresponding values calculated from the power law equation, when the compressive stress: $\Delta-0,25$ $\sigma_{10 \%} ; \quad \boldsymbol{\Delta}-0,35 \sigma_{10 \%} ; \circ-0,40 \div 0,45 \sigma_{10 \%} ; \bullet-0,50 \div 0,60 \sigma_{10 \%}$.

$$
=
$$

Synthesized joint prediction estimate $\bar{\varepsilon}_{c}\left(t_{e}\right)$ is a linear combination of individual predictions:

$$
\bar{\varepsilon}_{c}\left(t_{e}\right)=\sum_{i=1}^{i=n} \varphi_{i} \cdot \bar{\varepsilon}_{c(i)}\left(t_{i}\right),
$$

where:

$\varphi_{i}$ - i-th prediction weight;

$\bar{\varepsilon}_{c(i)}\left(t_{i}\right)$ - individual i-th prediction values.

Weights $\varphi_{i}$ selection criterion is the minimum of the

$$
=
$$

prediction $\bar{\varepsilon}_{c}\left(t_{e}\right)$ errors. Error minimum detection procedure is based on Lagrangian solutions (Gnip et al. 2007). If it is solved, in case of two prediction results, we obtain:

the influence coefficients for joint prediction results:

$\varphi_{(1)}=\frac{S_{r(2)}^{2}}{S_{r(1)}^{2}+S_{r(1)}^{2}}$,

$\varphi_{(2)}=\frac{S_{r(1)}^{2}}{S_{r(1)}^{2}+S_{r(2)}^{2}}$.

the weighted average of joint prediction results:

$$
\bar{\varepsilon}_{c}\left(t_{e}\right)=\frac{1}{S_{r(1)}^{2}+S_{r(2)}^{2}} \cdot\left[S_{r(2)}^{2} \cdot \bar{\varepsilon}_{c(1)}\left(t_{i}\right)+S_{r(1)}^{2} \cdot \bar{\varepsilon}_{c(2)}\left(t_{i}\right)\right] \text {, }
$$

the dispersion of such average:

$$
S_{\varepsilon_{c\left(t_{i}\right)}}^{2}=\frac{S_{r(1)}^{2} \cdot S_{r(2)}^{2}}{S_{r(1)}^{2}+S_{r(2)}^{2}} .
$$

According to equation (12) obtained joint prediction results weighted averages with a standard deviation $S_{r}=0.279 \mathrm{kPa}$, and the coefficient of determination $R^{2}=0.906 \%$ are presented in Fig. 4. Obviously, the combined prediction ensures greater reliability of the results than its individual components results.

In this paper, the regression equations (6) and (7) are used for evaluation of dependent $\bar{\varepsilon}_{c}\left(t_{i}\right)$ variable predicted values outside the independent variable experimental study $t_{i}$ (time) limits. These regression equations are useful for practical prediction (extrapolation). If the outgo outside of the experiment is small $\left(\left(t_{i}=10\right)\right.$ years $)$, then the error, related to the fact that the test limits relation form will change slightly, will be small and may be covered with a confidence interval (Gnip et al. 2007).

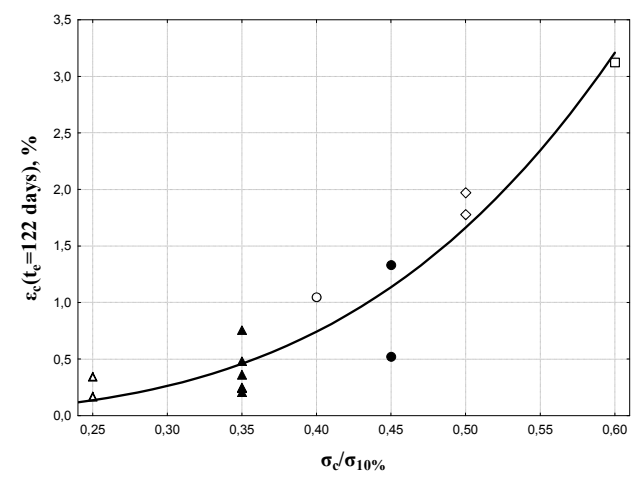

Fig. 4. Weighted averages of creep deformations predicted values when compressive stress is: $\Delta-0,25 \sigma_{10 \%} ; \boldsymbol{\Delta}-0,35 \sigma_{10 \%}$; $\circ-0,40 \sigma_{10 \%} ;-0,45 \sigma_{10 \%} ; \diamond-0,50 \sigma_{10 \%} ; \square-0,60 \sigma_{10 \%}$.

Extrapolating from the equation (6), obtained creep deformation patterns for prediction for up to 10 years can be sufficiently predicted using the relative creep deformations at time $t$ which under constant compressive stress $\sigma_{c}$ are calculated per unit stress and are called creep mobility:

$I_{c}(t)=\frac{\varepsilon_{c}(t)}{\sigma_{c}}$

where: $I_{c}(t)$ - comparative creep deformations at a fixed time $t$ occurring due to unit stress formed at time $t \leq 15 \mathrm{~s}$ after the start of the compression, $\mathrm{MPa}^{-1}$;

$\sigma_{c}-$ constant compressive stress at any point of time $t$, $M P a$;

$t$ - countdown.

Knowing creep mobility $I_{c}(t)$, it is allowed to move from stress $\sigma_{c}$ to full deformations of stone wool slabs under compression: 


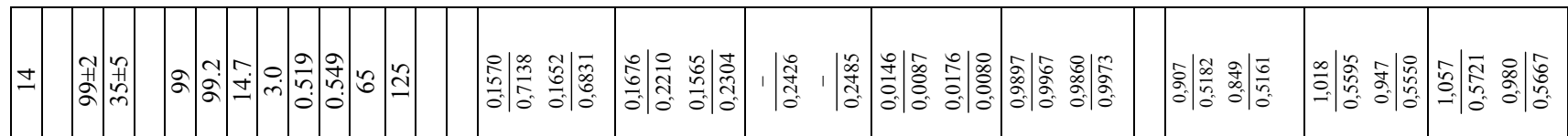

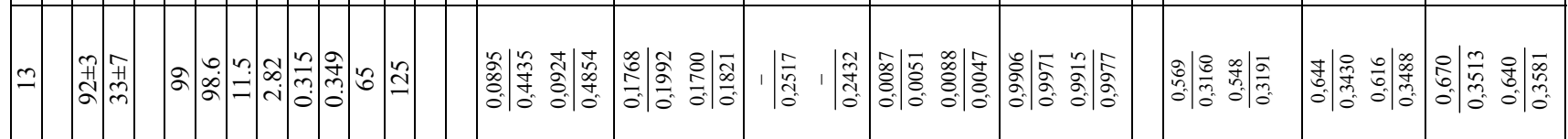

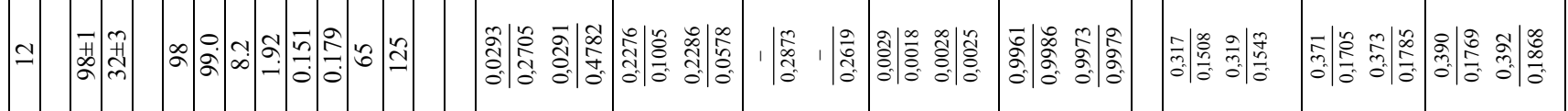

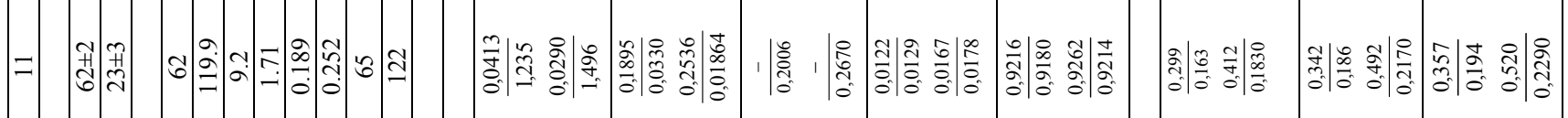

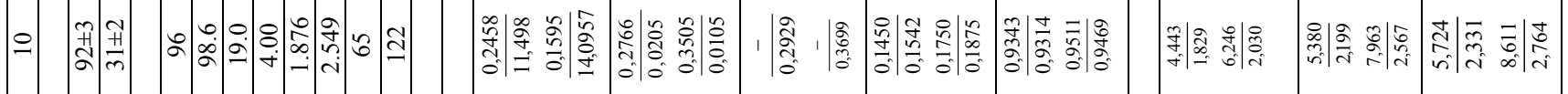

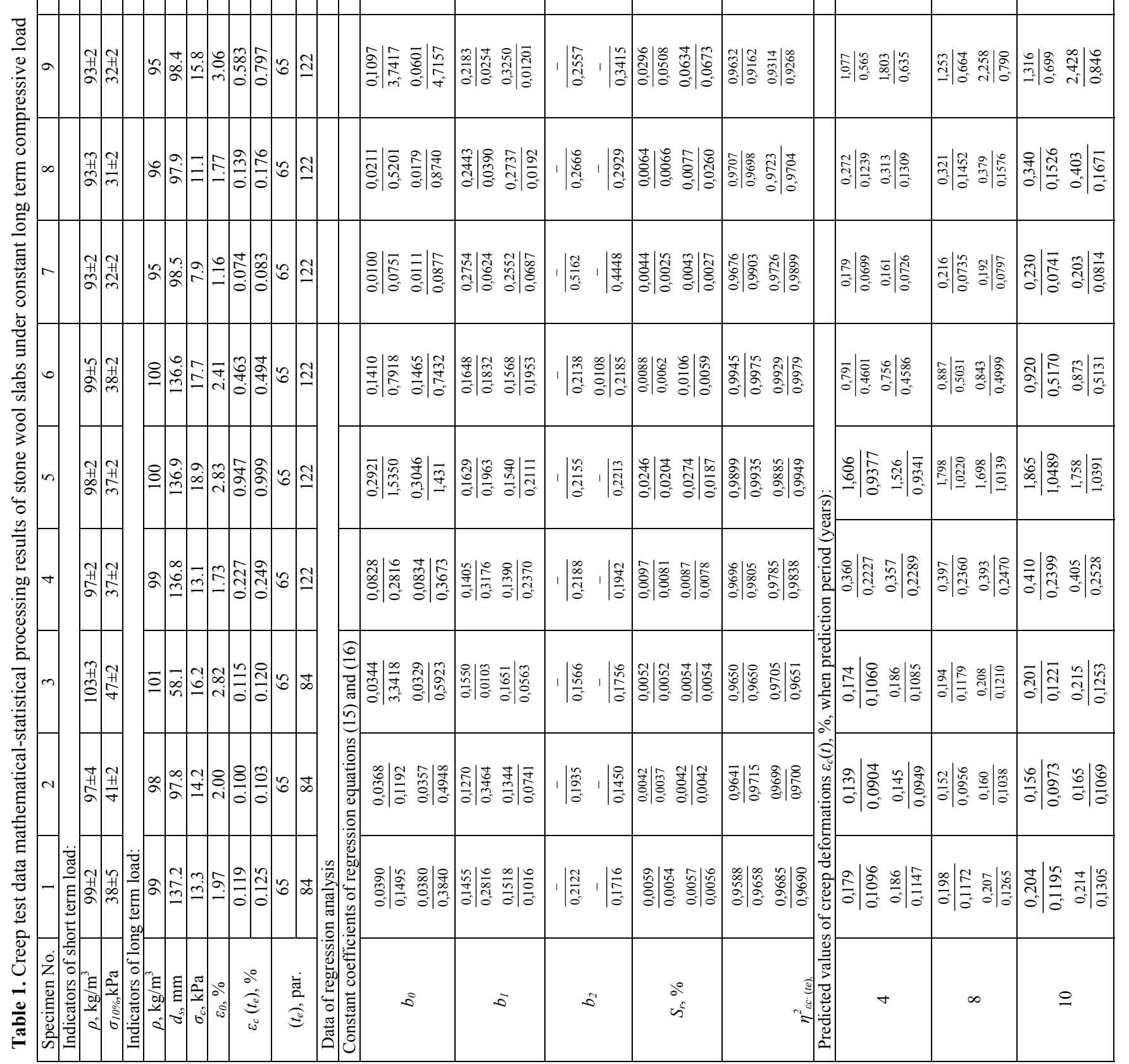


$\varepsilon(t)=\sigma_{c}\left[\frac{1}{E}+I_{c}(t)\right]$

and conversely, from deformation to stress:

$\sigma_{c}=\frac{\varepsilon(t)}{\frac{1}{E}+I_{c}(t)}$,

where: $E-$ modulus of elasticity of relatively instantaneous deformation taking place at the time of loading of stone wool specimens, and it is equal to $\frac{\sigma_{c}}{\varepsilon_{0}}, M P a$.

Fig. 5 presents the dependence of stone wool slabs creep mobility $I_{c}(t), M P a$, on compressive stress ratio $\frac{\sigma_{c}}{\sigma_{10 \%}}$. The corresponding creep mobility values have been calculated according to creep deformation values, which have been determined according to equation (6) with calculation parameters $\left(b_{0}\right.$ and $\left.b_{1}\right)$ obtained on the basis of direct experiment ( $t_{e}=122$ days) results. This dependence can be approximated by the regression equation:

$$
I_{C}\left(t_{e=122 \mathrm{days}}\right)=3,05\left(\frac{\sigma_{c}}{\sigma_{10 \%}}\right)^{2,71}
$$

with average standard deviation $S_{r}=0.081 \mathrm{kPa}$ and coefficient of determination $R^{2}=0.845 \%$.

The paper attempts to analyse experimental values of the stone wool slabs creep deformations $\varepsilon_{c r}$ determined by the 122-days direct experiment dependence on long term compressive stress $\sigma_{c}=0.35 \sigma_{10 \%} \mathrm{kPa}$, and on critical deformation values $\varepsilon_{c r} \%$.

Tested dependence has been approximated by linear multiple regression equation:

$$
\varepsilon_{c}\left(t_{e}\right)=-0.814+0.074 \sigma_{c}+0.045 \varepsilon_{c r}
$$

with an average standard deviation $S_{r}=0.104 \%$ and multiple coefficient of determination $R_{\varepsilon_{C} \cdot \sigma_{C} \cdot \varepsilon_{C R}}^{2}=0.922$, showing experimental values variation of stone wool creep deformations which have been by $92 \%$ dependent on compressive stress changes and specific values of deformations (corresponding to the start of significant decrease in the initial firmness of the product), and by $8 \%-$ on other factors the influence of which has not been assessed yet in the adopted scheme. Fig. 6 compares experimental deformation values of stone wool specimens obtained during the direct experiment $t_{e}=122$ days) and the values calculated from the regression equation (18).
The experimental values of $\varepsilon_{c}\left(t_{e}\right)$ and the relative difference $\Delta \bar{\varepsilon}_{c}\left(t_{e}\right), \%$, of the calculated values $\bar{\varepsilon}_{c}\left(t_{e}\right)$ have been calculated according to the formula:

$\Delta \varepsilon_{c}\left(t_{e}\right)=\frac{\varepsilon_{c}\left(t_{e}\right)-\bar{\varepsilon}_{c}\left(t_{e}\right)}{\varepsilon_{c}\left(t_{e}\right)} \cdot 100$,

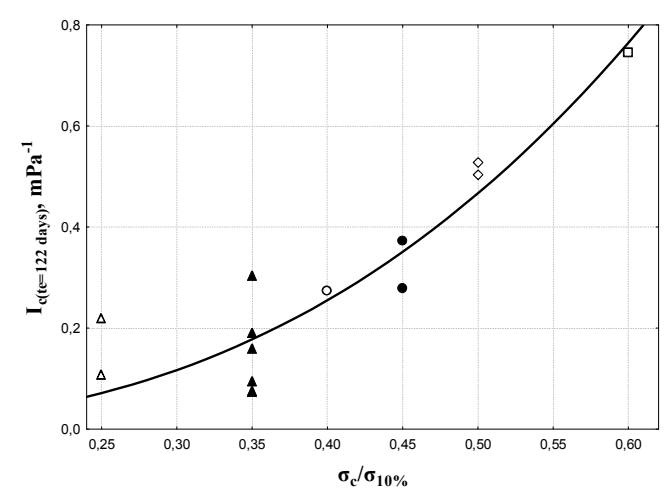

Fig. 5. Stone wool slabs creep mobility dependence on compressive stress ratio.

Based on the data (Fig. 6(b)) it may be noted that the predicted values of creep deformations for the same time period as the direct experimental time $t_{e}=122$ days can be calculated from equation (16) using $\sigma_{c}=0.35 \sigma_{10 \%}$ and $\varepsilon_{c r}$ values with the average relative error ranging from $+38 \%$ to $-16.0 \%$.

In the European countries it is an adopted practice to predict and declare creep deformations of stone wool slabs in 10 years period. In this paper, the performed long-term studies allow creep deformations $\varepsilon_{c}(t)$ for extrapolation up to 10 years in accordance with the type of (6) empirical equations, the coefficients of which are presented in Table 1. In such prediction it is assumed that compressive creep deformations are formed under the influence of many factors, and the influence of individual factors cannot be distinguished.

Thus, long-term creep process is not associated with any specific factors, but only with the passage of time, and extrapolations are entered into the simplest prediction period value introduction and the formula which describes the trend. Trend is a regression in time (Vaitkus 2007).

As already mentioned, creep deformations of the stone wool slab specimens can be calculated with sufficient accuracy for practical needs by linear multiple regression equation (16). According to the 10 years prediction of creep deformations values calculated from (6) and longterm experimental data, the possibility to predict creep deformations values $\varepsilon_{c}(t=10) \%$ according to such indicators as $\sigma_{c}=0.35 \sigma_{10 \%}, \mathrm{kPa}$, and the critical deformation $\varepsilon_{c r}$ (determined during the direct experiments) has been examined. 
a)

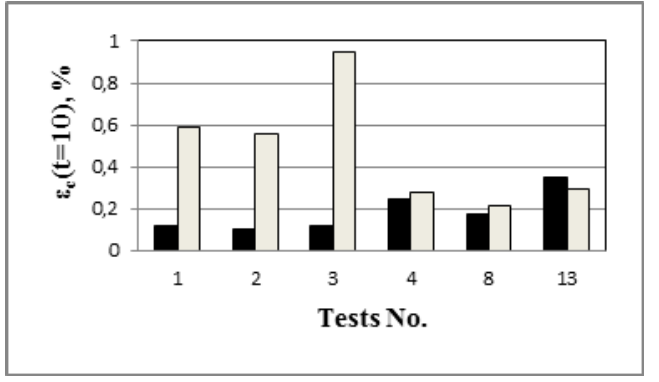

b)

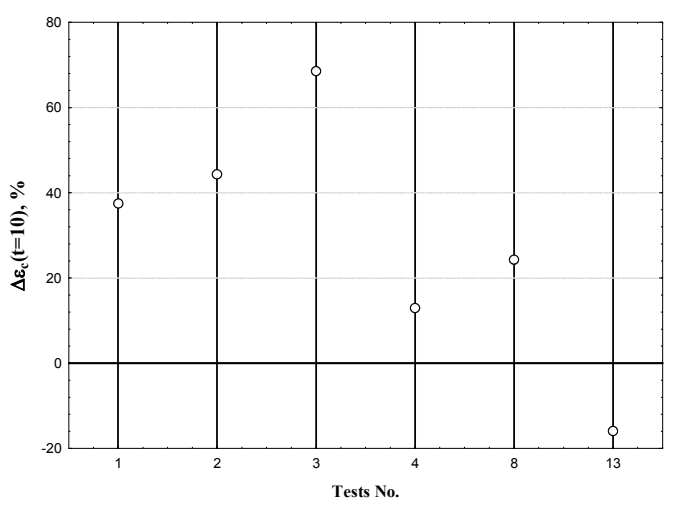

Fig. 6. Absolute values of creep deformations of stone wool specimens (a) and relative experimental and calculated according to equation (19) value differences (b): - - direct experiment $\left(\mathrm{t}_{\exp }=122\right.$ days) results; $\square-$ values calculated according to equation (18); $\bigcirc-$ relative differences according to equation (19).

Then, based on linear regression equation (18) we obtain (Fig. 7):

$$
\bar{\varepsilon}_{c}(t=10)=0.556-0.034 \sigma_{c}+0.068 \varepsilon_{c r},
$$

with the mean standard deviation $S r=0.117$ and multiple coefficient of determination $R^{2}=0.745 \%$, showing that extrapolated creep deformations $\varepsilon_{c}(t=10)$ variation is by $75 \%$ dependent on changes in compressive stress $\sigma_{c}$ and deformation $\varepsilon_{c r}$ values, and by $15 \%$ - on other factors the influence of which has not been assessed yet in the adopted scheme.

Fig. 8 presents the comparison of predicted values of creep deformations for 10 years period when they are calculated from the 65 and 122 days duration of the direct experiments data. As we know, according to (EN 1606:2013) requirements direct experiment time is 122 days. The relative difference between the two predicted values is calculated according to the formula:

$\Delta \bar{\varepsilon}_{c}(T=10)=\frac{\bar{\varepsilon}_{c}(T=10)_{65 \text { days }}-\bar{\varepsilon}_{c}(T=10)_{122 \text { days }}}{\bar{\varepsilon}_{c(}(T=10)_{122 \text { days }}} \cdot 100$,

where: $\Delta \bar{\varepsilon}_{c}(T=10)_{65 \text { days }}$ and $\Delta \bar{\varepsilon}_{c}(T=10)_{122 \text { days }}-$ predicted creep deformations values for the period of 10 years on the basis of accordingly 65 and 122 days of direct experiments data.
According to Fig. 8(b) data, it can be noted that extrapolating from the power law (6) equation predicted creep deformations of stone wool slabs for the period of 10 years can be evaluated also from 65 days of direct experimental data. In this case,- the additional relative error of predicted values, compared with 122 days experiment will be ranging from $-17.9 \%$ to $+6.4 \%$ (except for three distinct deviations reaching $-45.8 \%$, $33.5 \%$, and $-31,3 \%$ ). These practically acceptable values $\bar{\varepsilon}_{c}(t=10)$ differences can be explained by the high coefficients of determination $R_{\varepsilon_{c} \cdot t}^{2}$ values (Table 1 ).
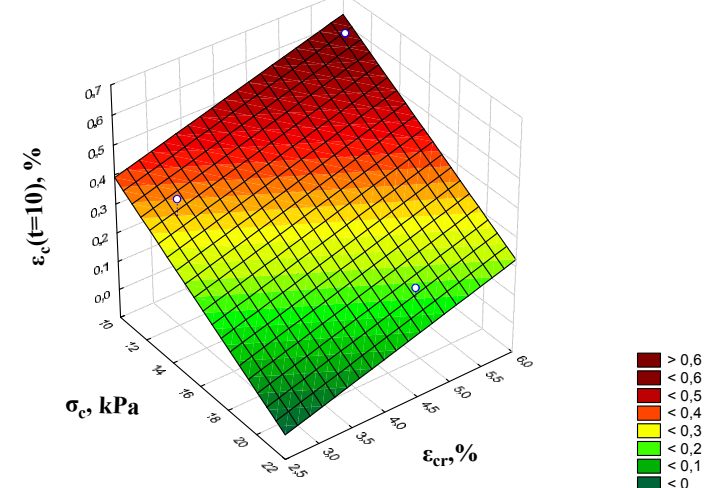

Fig. 7. Graphical interpretation of regression dependence (20) when predicting creep deformations of stone wool slabs exposed to constant compressive load $\sigma_{c}=0,35 \cdot \sigma_{10 \%}$ for 10 years.

a)

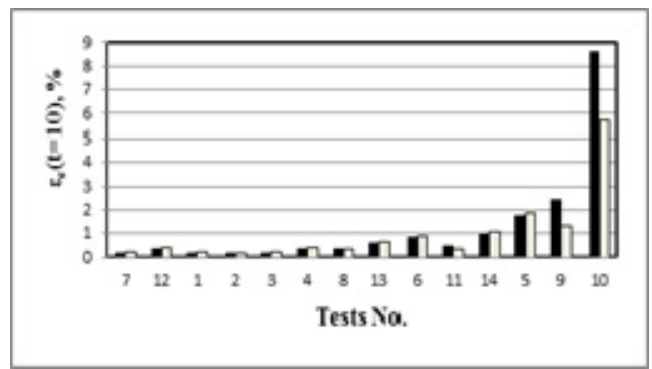

b)

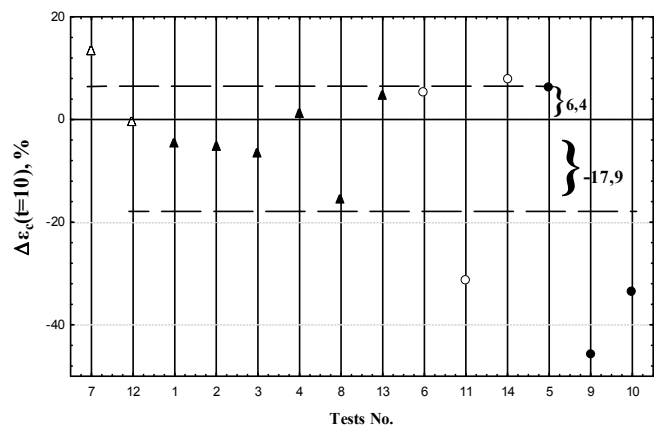

Fig. 8. Predicted values of creep deformations (a) and relative differencies of predicted values (b) calculated according to power law (6) equation and direct experiments data (Table 1): - predicted values in accordance of 122 days data; $\square$ - in accordance with 65 days data; Dots mark the relative differencies on the basis of equation (21): $\Delta-0,25 \sigma_{10 \%} ; \boldsymbol{\Delta}$ $0,35 \sigma_{10 \%} ; \quad \bigcirc-(0,40-0,45) \sigma_{10 \%} ; \bullet-(0,50-0,60) \sigma_{10 \%}$. 
These values show that for evaluation of calculated creep deformations empirical equations are close to the functional dependence $\varepsilon_{c}=F(t)$ which are limited to specific conditions of the test. For example, the minimum $\eta^{2} \varepsilon_{c} \cdot t$ values are equal to $R_{\varepsilon_{c} \cdot t}^{2}=0.9973$ (see Table 1, series of 12 tests, the experimental duration of 122 days), the correlation ratio of $R \varepsilon_{c} \cdot t=0.9986 \approx 1$ approves the strict direct connection (Figure $8(\mathrm{a})$ and Figure $8(\mathrm{~b})$ ). This suggests that using the power law (6) equation, extrapolation can be increased up to 60 times.

\section{Conclusions}

1. It was found out that the creep deformations for the period of 10 years can be predicted on the basis of data of 65 days duration experiments instead of the 122 days which are indicated in the standard.

2. Extrapolating from the equation (6), obtained creep deformation patterns for prediction for up to 10 years can be sufficiently predicted using the relative creep deformations at time $t$ which under constant compressive stress $\sigma_{c}$ are calculated per unit stress and are called creep mobility (equation (14)).

3. According to the 10 years prediction of creep deformations values calculated from (6) and longterm experimental data, the possibility to predict creep deformations values $\varepsilon_{c}(t=10) \%$ according to such indicators as $\sigma_{c}=0.35 \sigma_{10 \%}, k P a$, and the critical deformation $\varepsilon_{c r}$ (determined during the direct experiments)- has been examined.

4. Predicted values of creep deformations of stone wool slabs (density of $(95-108) \mathrm{kg} / \mathrm{m}^{3}$ and thickness of (60-140) mm with (3.4-6.1) \% of binder) exposed to $(0.25-0.35) \sigma_{10 \%}$ load make $0.16-0.64 \%$.

\section{References}

Bergonnier, S.; Hild, F.; Rieunier, J. B.; Roux, S., 2005. Strain heterogeneities and local anisotropy in crimped glass wool. Journal of Materials Science, 40(22), pp. 5949-5954. http://dx.doi.org/10.1007/s10853-005-5068-8

Gnip, I.; Vèjelis, S.; Keršulis, V.; Vaitkus, S., 2005. Predicting the Deformability of Expanded Polystyrene in Short-Term Compression. Mechanics of Composite Materials, 41, pp. 105 - 109. http://dx.doi.org/10.1007/s11029-005-0037-5

Gnip, I.; Vaitkus, S.; Keršulis,V.; Vejjelis, S., 2007. Deformability of Expanded Polystyrene under Short-Term Compression. Mechanics of Composite Materials, 43(5), pp. 433-444. http://dx.doi.org/10.1007/s11029-007-0041-z

Gnip, I.; Vaitkus, S.; Keršulis,V.; Vejelis, S., 2008. Confidence intervals of long-term prediction and synthesis of creep compliance prediction estimates for expanded po-lystyrene (EPS) under compressive stress. Polym. Test, 27, pp. 378-391. http://dx.doi.org/10.1016/j.polymertesting.2008.01.005
Gnip, I.; Keršulis,V.; Vaitkus, S.; Vèjelis, S., 2009. Predicting the deformability of mineral wool slabs under constant compressive stress. Construction and building Materials, 3(23), pp. $1928-1934$.

http://dx.doi.org/10.1016/j.conbuildmat.2008.09.008

Gnip, I.; Vèjelis, S.; Vaitkus, S., 2012a. Thermal conductivity of expanded polystyrene (EPS) at $10^{\circ} \mathrm{C}$ and its conversion to temperatures within interval from 0 to $50{ }^{\circ} \mathrm{C}$. Energy and Buildings, 52, pp. 107- 111.

http://dx.doi.org/10.1016/j.enbuild.2012.05.029

Gnip, I.; Vejjelis, S.; Vaitkus, S., 2012b. Long - term prediction of creep strains of mineral wool slabs under constant compressive stress. Mech Time-Depend Mater, in press. Availabl at: http://dx. doi.org/10.1007/s11043-011-9152-y.

Gnip, I.; Vaitkus, S.; Vejjelis, S., 2013. An estimated prediction of the deformability of mineral wool (MW) slabs under longterm compressive stress. Construction and Building Materials, 38, pp. 675-680.

http://dx.doi.org/10.1016/j.conbuildmat.2012.07.043

Horvath, J. S., 1997. The compressible inclusion function of EPS Geofoam. Geotextiles and Geomembranes. http://dx.doi.org/10.1016/S0266-1144(97)00008-3

Horvath, J. S., 1998. Mathematical modeling of stress-straintime behavior of geosyn-thetics using the Findley equation: general theory and application to EPS-block geofoam. Manhattan College Research Report Nr. CE/GE-98-3. 35 p.

Karamanos, A. K.; Giama, E.; Papadopoulos, A. M., 2007. Environmental impact of fibrous insulating materials operating in harsh temperature conditions. In Proceedings of the 1st Conference on Environmental Management. Engineering, Planning and Economics (CEMEPE 07), June 24-28, 2007, Skiathos island, Greece. pp. 1889-1894.

Leal, A. A.; Deitzel, J. M.; Gillespie, J. W., 2009. Compressive strength analysis for high performance fibers with different modulus in tension and compression. Composite Materials, 43(06), pp.661-674. http://dx.doi.org/10.1177/0021998308088589

EN 13162:2012. Thermal insulation products for buildings factory made mineral wool (MW) products - specification. 2012. 34 p. (in Lithuanian)

EN 1606:2013. Thermal insulating products for building applications. Determination of compressive creep, 200615 p. (in Lithuanian)

EN 826:2013. 1t. Thermal insulating products for building applications. Determination of compression behaviour, 2013. 12 p. (in Lithuanian)

Merkel, H., 2002. Wärmeschutz erdberührter Beuteile (Permeterdämmung) - Dämmstoffe, Beanspruchungen, Konstruktionen. Bauphysik Kalender, Berlin, Verlag Ernst\&Sohn. (in Germany).

Mihlaynlar, E.; Dilmaç, Ş.; Güner, A., 2008. Analysis of the effect of production process parameters and density of expanded polystyrene insulation boards on mechanical properties and thermal conductivity. Mater. Des. 29, pp. 344-352. http://dx.doi.org/10.1016/j.matdes.2007.01.032

Vaitkus. S., 2007. Experimental investigations of strength and deformation properties of expanded polystyrene under short and long-term compressive loading. Summary of doctoral dissertation. Technological Sciences, materials engineering (08T), 2007, Vilnius, Lithuania. 24 p.

Žiliukas, A., 2004. Mechanics of materials. 2004, Kaunas, Lithunia. 463-471 p. ISBN 9955-09-729-9. (in Lithuanian). 